\title{
Hemşirelerin oryantasyon programında kullanılan kardiyovasküler modül ĕgitiminin etkinliği
}

\author{
Sevda TÜREN ${ }^{\mathrm{a}}$, Filiz ÇETINKAYA IŞIK ${ }^{\mathrm{b}}$, Necibe UZUN MORGÜL ${ }^{\mathrm{c}}$
}

\section{ÖZET}

Amaç: Oryantasyon amacıyla yapılan eğitim; kurumda yeni işe başlayan veya çalıştığı alandan farklı bir bölümde görevlendirilen bireylere, çalışacakları alana özgü bilgi, beceri ve tutum kazandırmak için planlanan eğitimlerdir. Çalışma, hemşirelik oryantasyon programı dahilinde gerçekleştirilen kardiyovasküler modül eğitiminin etkinliğini değerlendirmek amacıyla yapıldı. Yöntem: Tanımlayıcı ve retrospektif olarak tasarlanan araştırmanın evrenini 138 hemşirenin veri kayıtları oluşturdu. Çalışma, JCI standartları doğrultusunda hazırlanmış bir hastanenin oryantasyon programı dahilinde gerçekleştirildi. Hemşirelere ait demografik veriler kurum kayıtlardan elde edilirken, hemşirelerin eğitim öncesi ve sonrası kardiyovasküler bilgi düzeyi ise 25 soruyu içeren ön test-son test puanlarından hesaplandı. Her soru dört puan üzerinden toplam 100 puan olarak değerlendirildi. Veriler SPSS 17.0 programında, tanımlayıcı istatistik, ANOVA ve bağımlı örneklerde $t$ testi kullanılarak belirlendi. Bulgular: Çalışmaya dahil edilen hemşirelerin yaş ortalaması $24.0 \pm 3.1$ (19-37 yaş) bulundu. Çalışmaya katılanların \%68.1'ini ( $\mathrm{n}=94)$ lisans mezunu hemşireler oluştururken, \%55.1'i $(\mathrm{n}=76)$ daha önce herhangi bir kurumda çalışmadığını bildirdi. Ön testten alınan puanların ortalaması $58.5 \pm 15.1$ iken, son test puanlarının ortalaması $89.4 \pm 10.3$ olarak saptandı. Alt gruplara göre yapılan analizlerin tamamında kardiyovasküler modül eğitimin etkili olduğu belirlendi. Sonuç: Oryantasyon programlarında yer alan kardiyovasküler modül eğitimlerin kardiyovasküler kliniklerde (yetişkin ve pediatrik) görev alacak hemşirelerin eğitim düzeyini arttırdığı görüldü.

Anahtar kelimeler: Eğitim, kardiyovasküler hemşirelik, oryantasyon programı

\section{Effectiveness of cardiovascular module training used in nurses' orientation program}

\section{ABSTRACT}

Objective: Orientation training aims to train individuals who are newly-recruited or assigned to a department different from their field of study to help them gain knowledge, skills and attitudes that are specific to the field in which they will work. The study was conducted to evaluate the effectiveness of cardiovascular module training carried out within the nursing orientation program. Methods: The data of 138 nurses constituted the universe of the descriptive and retrospective study. The study was carried out with in the orientation program of a hospital prepared in accordance with JCI standards. Demographic data of nurses was obtained from institutional records; the level of cardiovascular knowledge before and after training of nurses was calculated from pre-test and posttest scores containing 25 questions. Four points were given for each answer and total test 100 points. The data was analyzed by descriptive statistics, paired t test and ANOVA using SPSS 17.0. Results: The mean age of the nurses included in the study was 24.0 \pm 3.1 (19-37 years). Among the participants, 94 (68.1\%) nurses had college degree and $55.1 \%(n=76)$ reported that they had not previously worked in any institution. Mean of the scores from the pretest was $58.5 \pm 15.1$ and the mean of the post test scores was $89.4 \pm 10.3(\mathrm{p}<0.001)$. Cardiovascular module training was found to be effective across all educational and experience levels. Conclusion: Cardiovascular module training included in the orientation programs increased the education level of the nurses who will work in the cardiovascular clinics (adult and pediatric).

Key words: Education, cardiovascular nursing, orientation program

\footnotetext{
Geliş Tarihi:19.03.2020 Kabul Tarihi: 17.05.2020

${ }^{a}$ T.C. İstanbul Kültür Üniversitesi Sağlık Bilimleri Fakültesi Hemşirelik Bölümü, İstanbul, Türkiye, e-posta: sevdamercanhm@ hotmail.com ORCID: 0000-0003-1123-5879

'Sağlık Bilimleri Üniversitesi İstanbul Mehmet Akif Ersoy Göğüs ve Kalp Damar Cerrahisi Eğitim ve Araştırma Hastanesi, İstanbul, Türkiye, e-posta:, faramis77@gmail.com ORCID: 0000-0003-2689-755X

'Sağlık Bilimleri Üniversitesi İstanbul Mehmet Akif Ersoy Göğüs ve Kalp Damar Cerrahisi Eğitim ve Araştırma Hastanesi, İstanbul, Türkiye, e-posta:, necibeuzun77@gmail.com ORCID: 0000-0002-6799-3081

Sorumlu Yazar/Correspondence: Sevda Türen e-mail: sevdamercanhm@hotmail.com
}

Çalı̧̧ma 26-28 Ekim 2018'de Antalya'da gerçekleştirilen Uluslararası katılımlı Türk Kalp ve Damar Cerrahisi Derneği 15. Kongresi'nde sözlü bildiri olarak sunulmuştur.

Atıf: Türen S, Çetinkaya Işık F, Uzun Morgül N. Hemşirelerin oryantasyon programında kullanılan kardiyovasküler modül eğitiminin etkinliği. Sağglk ve Yaşam Bilimleri Dergisi 2020;2(1):1-5.

Citation: Türen S, Çetinkaya Işık F, Uzun Morgül N. Effectiveness of cardiovascular module training used in nurses' orientation program. Journal of Health and Life Science 2020;2(1):1-5. 


\section{GíRiş}

Sağlık alanında gerçekleşen bilimsel ve teknolojik gelişmelere paralel olarak, sağlık profesyonellerinin bu değişism ve gelişime uyum sağlamaları beklenmektedir. $^{1-2}$ Sağlık sisteminde önemli yere sahip olan hemşireler, gerek alanında yetkin olabilmek gerekse kaliteli hasta bakımı verebilmek için kendilerini geliştirmelidir. Bunun sağlanmasında mezuniyet sonrası verilen mesleki eğitimler önemli bir yere sahiptir. $^{1-4}$

Oryantasyon, Fransızca kökenli bir kelimedir ve "uyumlu hale getirme, yönlendirme" anlamına gelmektedir. ${ }^{5}$ Çalışanların işe başladıklarında veya aynı kurumda farklı bir bölüme geçtiklerinde oryantasyon eğitimi ile çalışacakları alana özgü bilgileri edinmiş olurlar. ${ }^{4-6}$ Oryantasyon programı içerisinde yer alan modül (öbek, parça) eğitimler ise, bir meslek alanının öğretim programı dahilinde kendi içerisinde bir bütünlük oluşturan eğitimlerdir. ${ }^{7-8}$

Kardiyovasküler alan gibi ileri bilgi ve beceri gerektiren alanlarda çalışacak hemşirelerin yeterli bilgiye sahip olmasında güncel bilgilerin aktarılması büyük önem taşımaktadır. Dolayısıyla, hemşirelerin çalışacakları alana özgü eğitim almaları gerekir.,9-11 Kardiyovasküler modül eğitimler, kardiyovasküler kliniklerde (yetişkin ve pediatrik olmak üzere kardiyoloji ve kalp damar cerrahisi klinikleri) çalışacak hemşirelerin alana özgü bilgi ve becerilerinin geliştirmesi hedeflenerek oluşturulmuştur. Uluslararası sağlık alanında akredite olan hastanelerde (Joint Commission InternationalJCI- belgesine sahip) çalışanlara verilen bu eğitimlerin etkinliğinin değerlendirilmesi beklenmektedir. $\mathrm{Bu}$ çalışma ise, hemşirelik oryantasyon programı dahilinde gerçekleştirilen kardiyovasküler modül eğitiminin etkinliğini değerlendirmek amacıyla yapılmıştır.

\section{YÖNTEM}

Tanımlayıcı olarak tasarlanan araştırma, retrospektif ve tek merkezli olarak gerçekleştirildi. Araştırma İstanbul'da Avrupa yakasında bir eğitim ve araştırma hastanesinde yapıldı. Örneklemi 2018 yılı son dönemi göreve başlayan (Eylül-Aralık) tüm hemşirelerin veri kayıtları $(\mathrm{n}=138)$ oluşturdu. Çalışma uluslararası alanda akredite olmuş bir hastanenin JCI standartları doğrultusunda hazırlanmış bir oryantasyon programı dahilinde gerçekleştirildi.

Çalışmanın yapıldığı kurumda hemşirelere genel oryantasyon eğitimi içerisinde, klinik alana özgü eğitim verilmeden önce ön test uygulanmakta, sonrasında alanında uzman hekim ve hemşireler tarafindan iki gün süren kardiyovasküler modül eğitimi verilmektedir. Eğitimin değerlendirilmesinde ise, ön test ile aynı soruları içeren son test uygulanmaktadır. Uygulanmış olan testte eğitimde anlatılan kardiyovasküler anatomi ve fizyoloji, yetişkin ve pediatrik kardiyak hastalıklar, hemşirelik bakımı, taburculuk ve hasta eğitimi konuları yer almaktadır.

Çalışmanın yapılabilmesi kurumdan (karar no:2018/314) gerekli yazılı izin alındı. Hemşirelere ait demografik veriler kurum kayıtlardan elde edilirken, kardiyovasküler bilgi düzeyi ise 25 soruyu içeren ön test-son test puanlarından hesaplandi. Her soru dört puan üzerinden toplam 100 puan olarak değerlendirildi.

Veriler SPSS 17.0 programında tanımlayıcı istatistik, ANOVA, bağımlı ve bağımsız örneklerde $\mathrm{t}$ testi kullanılarak ve \%95 güven aralığı esas alınarak analiz edildi. Sonuçlar yorumlanırken istatistiksel anlamlılık düzeyi $\mathrm{p}<0.05$ olarak kabul edildi.

\section{BULGULAR}

Kayıtlar incelendiğinde; hemşirelerin \%81.9'unu kadınların oluşturduğu ve yaş ortalamalarının $24.0 \pm 3.1$ (minimum 19 ve maksimum 37 yaş) olduğu saptandı. Öğrenim durumlarına bakıldığında, lisans düzeyinde öğrenim gören hemşirelerin sayısının daha fazla olduğu $(\% 68.1, \quad n=94)$ belirlendi. Mesleki deneyim açısından değerlendirildiklerinde ise, hemşirelerin \%55.1 $(n=76)$ oranında daha önce herhangi bir iş deneyiminin olmadığı görüldü (Tablo 1).

Tablo 1. Hemşirelerin sosyo-demografik özelliklere göre dağılımı

\begin{tabular}{|c|c|c|}
\hline Ort \pm SD (Min-Max) & $\mathbf{n}$ & $\%$ \\
\hline $24.0 \pm 3.1(19-37)$ & & \\
\hline \multicolumn{3}{|l|}{ Cinsiyet } \\
\hline Kadın & 113 & 81.9 \\
\hline Erkek & 25 & 18.1 \\
\hline \multicolumn{3}{|l|}{ Medeni durum } \\
\hline Evli & 18 & 13.0 \\
\hline Bekar & 120 & 87.0 \\
\hline \multicolumn{3}{|l|}{ Öğrenim durumu } \\
\hline Lise & 41 & 29.7 \\
\hline Ön Lisans & 3 & 2.2 \\
\hline Lisans & 94 & 68.1 \\
\hline \multicolumn{3}{|l|}{ Mesleki deneyim } \\
\hline Deneyim yok & 76 & 55.1 \\
\hline $0-4$ y1l & 54 & 39.1 \\
\hline $5-9$ y1l & 6 & 4.3 \\
\hline 10 yıl ve üzeri & 2 & 1.5 \\
\hline $\begin{array}{l}\text { Daha önce eğitim alma } \\
\text { durumu }\end{array}$ & 62 & 44.9 \\
\hline Evet & 76 & 55.1 \\
\hline Hayır & & \\
\hline
\end{tabular}

Daha önce mesleki deneyimi olan hemşirelerin $\% 21.7$ 'sinin $(n=30)$ yetişkin kardiyovasküler cerrahi, \%18.8'inin $(\mathrm{n}=26)$ yetişkin kardiyoloji ve \%4.4'ünün 
ise $(n=6)$ pediatrik (pediatrik kardiyoloji/pediatrik kalp damar cerrahisi) kliniklerde görev yaptığ 1 saptand1 (Şekil 1). Mesleki deneyimi olan hemşirelerin tamamının (\%54.9, $\mathrm{n}=62)$ daha önce çalıştıkları kurumda mesleki eğitim aldığ belirlenirken; \%55.1'inin $(\mathrm{n}=76)$ daha önce hiç eğitim almadığı görüldü (Tablo 1).

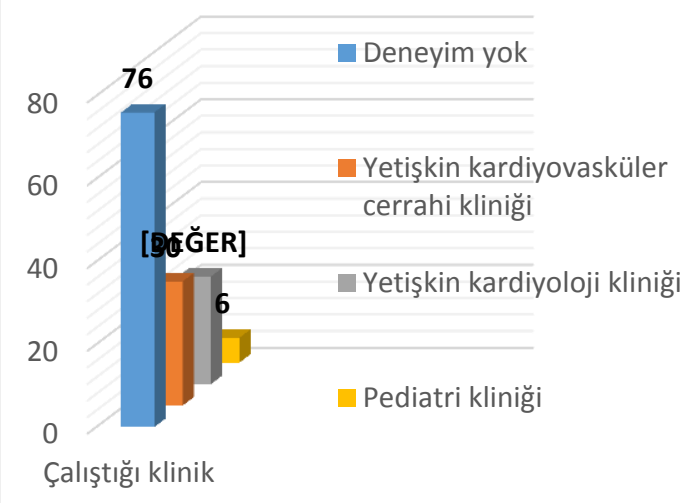

\section{Şekil 1. Hemşirelerin çalıştığı klinik alanlara göre dağılımı}

Hemşirelerin testlerden aldıkları puanlar cinsiyete göre değerlendirildiğinde; ön testte cinsiyetler arasında istatistiki açıdan anlamlı bir fark saptanmazken, son testte kadınların aldığı puanların erkeklerin puanlarına göre anlamlı düzeyde yüksek olduğu belirlendi. Her iki grupta da son test puanlarının ön test puanlarına göre anlamlı düzeyde yükseldiği saptandı (Tablo 2).

Tablo 2. Hemşirelerin ön ve son test puanlarının sosyodemografik özelliklere göre karşılaştırılması

\begin{tabular}{|c|c|c|c|}
\hline & Ön test & Son test & $\mathbf{P}$ \\
\hline $\begin{array}{lrl}\text { Ön } & \text { test } & \text { puan } \\
\text { ortalaması } & \\
\text { Son test } & \text { puan } \\
\text { ortalaması } & \\
\end{array}$ & $\begin{array}{l}58.5 \pm 1 \\
89.4 \pm 1\end{array}$ & $\begin{array}{l}(16-96) \\
(48-100)\end{array}$ & $*<0.001$ \\
\hline $\begin{array}{l}\text { Cinsiyet } \\
\text { Kadın } \\
\text { Erkek }\end{array}$ & $\begin{array}{l}58.4 \\
59.4\end{array}$ & $\begin{array}{l}90.3 \\
85.3 \\
\end{array}$ & $\begin{array}{l}*<0.001 \\
*<0.001\end{array}$ \\
\hline $\mathbf{p}$ & 0.768 & $* 0.026$ & \\
\hline $\begin{array}{l}\text { Öğrenim durumu } \\
\text { Lise } \\
\text { Önlisans } \\
\text { Lisans }\end{array}$ & $\begin{array}{l}58.4 \\
45.3 \\
59.0 \\
\end{array}$ & $\begin{array}{l}88.4 \\
72.0 \\
90.4 \\
\end{array}$ & $\begin{array}{l}*<0.001 \\
0.13 \\
*<0.001\end{array}$ \\
\hline p & 0.303 & $* 0.07$ & \\
\hline $\begin{array}{l}\text { Mesleki deneyim } \\
\text { Deneyim yok } \\
0-4 \text { yil } \\
5-9 \text { yil } \\
10 \text { yil ve üzeri }\end{array}$ & $\begin{array}{l}60.8 \\
55.6 \\
55.3 \\
64.0 \\
\end{array}$ & $\begin{array}{l}89.4 \\
89.3 \\
88.7 \\
96.0 \\
\end{array}$ & $\begin{array}{l}*<0.001 \\
*<0.001 \\
*<0.007 \\
0.29\end{array}$ \\
\hline p & 0.220 & 0.840 & \\
\hline
\end{tabular}

Not: Satır sonunda verilen $\mathrm{p}$ değerleri grup içi, sütunların altında verilen $\mathrm{p}$ değerleri gruplar arası karşılaştırmayı göstermektedir.

Testlerden alınan puanlar hemşirelerin öğrenim durumuna göre incelendiğinde ise; öğrenim durumu ve test puanları arasında istatistiki açıdan anlamlı fark tespit edildi (Tablo 2). Lise ve lisans mezunu hemşirelerin son test puanları arasında anlamlı bir fark görülmezken, ön lisans mezunu hemşirelerin hem lise hem de lisans mezunu hemşirelerden anlamlı düzeyde düşük puan aldıkları belirlendi (lise-ön lisans $\mathrm{p}=0.02$; ön lisans-lisans $\mathrm{p}=0.006$; lise-lisans $\mathrm{p}=0.52$ ). Ön lisans mezunu hemşirelere verilen eğitimin etkinliği rakamsal olarak anlamlı gözükse de, istatistiki düzeyde anlamlı bulunmadı (Tablo 2).

Hemşirelerin mesleki deneyimleri ile testlerden aldıkları puanlar karşılaştırıldığında; mesleki deneyimi olmayan ve 10 yldan az mesleki deneyime sahip olan hemşirelerin son test puanlarında istatistiki açıdan anlamlı fark saptanırken; 10 yıl ve üzeri mesleki deneyimi olan hemşirelere verilen eğitimin etkinliği rakamsal olarak anlamlı gözükse de, istatistiki düzeyde anlamlı bulunmadı (Tablo 2).

Hemşirelerin ön testten alınan puanlarının ortalaması $58.5 \pm 15.1$ olarak belirlenirken, son test puanlarının ortalaması $89.4 \pm 10.3$ olarak saptand1 $(\mathrm{p}<0.001)$. Hemşireler hem ön test hem de son testte kardiyovasküler anatomi ve fizyoloji konularından düşük puan alırken -ön test $n=32, \% 23.2$; son test $\mathrm{n}=85$, \%61.6- ; yetişkin ve pediatrik kardiyak hastalıklar konularından yüksek puan -ön test $n=137$, \%99.3; son test $\mathrm{n}=138$, \%100- almışlardır (ön test minimum 16 puan, maksimum 96 puan; son test minimum 48 puan, maksimum 100 puan) (Tablo 2). Yapılan alt grup analizlerde hemşirelerin yaş, öğrenim durumu ve çalışma deneyimi fark etmeksizin verilen kardiyovasküler modül eğitimin etkili olduğu görüldü (Tablo 2).

\section{TARTIŞMA}

Kardiyoloji ve kalp damar cerrahisi (hem yetişkin hem de pediatrik) kliniklerinde çalışan hemşireler, kaliteli ve etkin bakım verebilmek için ileri ve alana özgü hemşirelik bilgi ve becerisine ihtiyaç duymaktadırlar. $^{11} \mathrm{Bu}$ ihtiyacın giderilmesinde kuşkusuz hizmet içi mesleki eğitimlerin katkısı büyüktür. ${ }^{6,11}$ Yenilmez ve ark.'nın bir sağlık kuruluşunda JCI standartları doğrultusunda hazırlanmış oryantasyon programı dahilinde yaptığ çalışmada $\quad(\mathrm{n}=244)$, bu programların sağlık çalışanlarının işe uyumunda önemli olduğu vurgusu yapılmıştır. ${ }^{12}$ Atay ve ark. çalışmasında (n=185), hemşirelerin \%69.7'sinin hizmet içi eğitime ihtiyaç duydukları, buna rağmen hemşirelerin \%76.2'sine herhangi bir oryantasyon programı uygulanmadığı belirtilmiştir. ${ }^{4}$ Göçmen'in araştırmasında bu oran \%62.8 olarak bildirilmiştir. ${ }^{9} \mathrm{Bu}$ çalışmada ise, hemşirelerin \%55.1'inin $\quad(n=76)$ mesleki deneyimlerinin olmadığı ve bununla paralel olarak oryantasyon eğitim almadığı saptanırken; mesleki deneyimi olan hemşirelerin tamamının daha önce oryantasyon eğitimine katıldığ 
Hemşirelerin çalıştıkları alandaki mesleki deneyim, hemşirelerin hasta bakımı ve güvenliği açısından karşılaştıkları sorunun çözümünde önemli katkı sağlamaktadır. ${ }^{13-14}$ Yapılan bir çalışmada, deneyimli hemşirelerin $(n=130)$ hasta güvenliğine ilişkin risklerin farkındalıklarının yüksek olduğu ve daha etkin yönettikleri vurgusu yapılmıştır. ${ }^{15}$ Serbes ve Ulupınar-Alıcı'nın çalışmasında $(n=1038)$ özellikle genç ve mesleki alanda deneyimsiz hemşirelerin kendilerini mesleki alanda geliştirmek istedikleri (\%79.2) vurgulanırken; ${ }^{16}$ Öztürk ve ark.'nın çalışmasında $(\mathrm{n}=63)$ ise yeni işe başlayan hemşirelerin \%36.5'inin okulda öğrendiği mesleki bilgi ve beceride kendini yetersiz hissettiği bildirilmiştir. ${ }^{17}$ Literatürde yer alan bilgilere paralel olarak, bu çalışmada yer alan hemşirelerin de genç olması (yaş ortalaması 24.0 \pm 3.1 ) ve çoğunluğunun (\%55.1) mesleki alanda deneyimsiz olması kardiyovasküler modül eğitimin etkinliğinin değerlendirmesi bakımından uygun bir grubu oluşturmaktadır.

Ön lisans mezunu $(n=2)$ ve mesleki deneyimi 10 y1l ve üzerinde olan $(n=2)$ hemşirelere verilen eğitimin etkinliği rakamsal olarak anlamlı gözükse de, istatistiki düzeyde anlamlı bulunmadı. Bunun sebebinin bu grupta yer alan hemşire sayısının azlığından kaynaklandığı düşünülmektedir.

Ulupınar-Alıcı ve Çakır'ın çalışmasında hemşirelerin en fazla acil durum yönetimine ilişkin sorularda zorlandığı ve düşük puan aldıkları belirtilmiştir. ${ }^{18} \mathrm{Bu}$ çalışmada hemşirelerin; hem ön test hem de son testte kardiyovasküler anatomi ve fizyoloji ile ilgili sorulardan daha düşük puan aldıkları ve buna rağmen eğitim sonrası ön teste göre doğru yanıt verenlerde artış olduğu görülmektedir (doğru yanıt verme yüzdeleri: ön test \%23.2; son test \%61.6). Hemşirelerin temel tıp bilim dallarından olan anatomi ve fizyolojiyi iyi bilmeleri, özellikle girişimsel işlemlerin ve kritik hasta bakımlarının yapıldığ kardiyovasküler kliniklerde önem arz etmektedir. Ayrıca, hemşirelerin son test puanlarında anlamlı düzeyde artış olduğu (ön test puan ortalaması $58.5 \pm 15.1$; son test puan ortalamas1 $89.4 \pm 10.3$; $\mathrm{p}<0.001)$ saptanmıştır. Buna göre; hemşirelerin kardiyovasküler alana yönelik mesleki eğitim düzeyinin artışında verilen eğitimin etkili olduğu gösterilmiştir.

Whyte ve ark. yaptıkları çalışmada hemşirelerin bilgi düzeyi ve klinik performansın ayrılmaz bir biçimde bağlantılı olduğunu vurgulamıştır. ${ }^{19}$ Çelen ve ark.'nın çalışmasında $(n=90)$, hemşirelerin büyük çoğunluğu (\%91.1) verilen hizmet içi eğitimlerin işe olan ilgiyi arttırdığını ifade etmiştir. ${ }^{20}$ Oryantasyon eğitiminde yer alan eğitimlerin kardiyovasküler bilgi düzeyini arttırması ile klinik uygulamaya yansitılması hedeflenmektedir.
Çalışmanın alt grup analizlerinde verilen kardiyovasküler modül eğitimin hemşirelerde yaş, öğrenim durumu ve çalışma deneyimi fark etmeksizin etkili olduğu gösterilmiştir.

\section{SONUÇ}

Çalışmanın verileri analiz edildiğinde; yetişkin ve pediatrik kardiyovasküler kliniklerde görev alacak hemşirelerin oryantasyon programlarında yer alan kardiyovasküler modül eğitimin bilgi düzeyini arttırdığı saptandı. Hemşirelerin özellikle hem ön hem de son testte kardiyovasküler anatomi ve fizyoloji ile ilgili sorulardan daha düşük puan aldığı görüldü. Bu konuda hemşirelerin hem mezuniyet öncesi hem de mezuniyet sonrası eğitimlerle desteklenmesi önerilmektedir.

\section{KAYNAKLAR}

1. Şendir M, Şimşekoğlu N, Kaya A, Sümer K. Geleceğin teknolojisinde hemşirelik. SBÜ Hemşirelik Dergisi 2019;1(3):209-214.

2. Karahan A, Kav S. Hemşirelikte mesleki yetkinlik. Hacettepe Üniversitesi Hemşirelik Fakültesi Dergisi 2018;5(2):160-168.

3. Aytuğ-Kanber N, Gürlek Ö. Hemşirelerin uygulanan hizmet içi eğitim programından beklentileri ve bu program ile ilgili düşünceleri. Anadolu Hemşirelik ve Sağlık Bilimleri Dergisi. 2011;14(3):52-58.

4. Atay S, Gider D, Karadere G, Şenyüz P. Hastanede çalışan hemşirelerin hizmet içi eğitime yönelik görüşleri. Uluslararası İnsan Bilimleri Dergisi 2009;6(1):84-93.

5. Türk Dil Kurumu (TDK). www.tdk.gov.tr (Erişim: 27.08.2019)

6. Tiyek R. Oryantasyon eğitim programı etkinliğinin değerlendirilmesi: Bir araştırma. Çankırı Karatekin Üniversitesi SBE Dergisi 2014;5(1):333- 353.

7. Conway SE, Johnson JL, and Ripley TL. Integration of team-based learning strategies into a cardiovascular module. American Journal of Pharmaceutical Education 2010; 74 (2): 1-7.

8. Gömleksiz MN, Erten P. Mesleki ve teknik ortaöğretimde modüler öğretim programının uygulanmasında karşılaşılan güçlükler: nitel bir çalışma. Yüzüncü Yıl Üniversitesi Eğitim Fakültesi Dergisi. 2010;6(1):174-198.

9. Göçmen Z. Ameliyathane hemşirelerinin ameliyathane hemşireliği oryantasyon programı içeriğine ilişkin görüşleri. C.Ü. Hemşirelik Yüksekokulu Dergisi 2004;8(1): 12-24.

10. Yava A, Çiçek H, Tosun N, Yanmış N, Koyuncu A, Güler A, et al. Factors İnfluencing use of research results by cardiology and cardiovascular surgery nurses. Anatol J Clin Investig 2008;2(4):160-6.

11. Yava A, Koyuncu A, Demirkılıç U. Kardiyoloji ve kardiyovasküler cerrahi hemşireliği eğitiminde simülatör kullanımı. Türkiye Klinikleri J Cardiovasc Sci 2013;25(3):149-157.

12. Yenilmez K, Kaya S, Yalçın Balçık P, Dolgun NA. Hastanelerde işe alıştırma (oryantasyon) 
programının değerlendirilmesi: Hacettepe Üniversitesi hastaneleri örneği. Hacettepe Sağllk İdaresi Dergisi 2016;19(2):131-152.

13. Kardaş-Özdemir F, Akgün-Şahin Z. Hemşirelerin hasta güvenliği kültürü algıları: Kars ili örneği. ODU J Med. 2015;2:139-144.

14. Karahan A, Kılıçarslan-Törüner E, Abbasoğlu A, Ceylan A. Yeni mezun hemşirelerin hemşirelik becerilerinde yetkinlikleri ile ilgili algıları. Hacettepe Üniversitesi Sağlık Bilimleri Fakültesi Hemşirelik Dergisi 2012:62-72.

15. Çırp1 F, Doğan-Merih Y, Yaşar-Kocabey M. Hasta güvenliğine yönelik hemşirelik uygulamalarının ve hemşirelerin bu konudaki görüşlerinin belirlenmesi. Maltepe Üniversitesi Hemşirelik ve Sanat Bilimi Dergisi. 2009;2(3):2634.

16. Serbes Ş, Ulupınar-Alıcı S. Özel bir hastane grubunda çalışan hemşirelerin kurumdaki hizmet içi eğitim uygulamalarına ilişkin görüşleri. İ.Ü.F.N. Hem. Derg. 2010;18(2):98-105.
17. Öztürk H, Kurt \$̧, Mersinlioğlu-Serin G, Bayrak $\mathrm{B}$, Balık T, Demirbağ BC. Hastanelerde yeni işe başlayan hemşirelerin sorunları. ACU Sağlık Bil Derg 2016(4):189-201.

18. Ulupınar-Alıcı S, Çakır A. Hemşirelerin özel bir hastanede uygulanan klinik oryantasyon programına ilişkin görüşleri. Maltepe Üniversitesi Hemşirelik Bilim ve Sanatı Dergisi 2009;2(1): 4556.

19. Whyte J, Ward P, Eccles DW. The relationship between knowledge and clinical performance in novice and experienced critical care nurses. Heart Lung 2009;38(6):517-25.

20. Çelen Ö, Karaalp T, Kaya S, Demir C, Teke A, Akdeniz A. Gülhane Askeri Tıp Fakültesi Eğitim Hastanesi Yoğun Bakım ünitelerinde görev yapan hemşirelerin uygulanan hizmet içi eğitim programlarından beklentileri ve bu programlar ile ilgili düşüncelerinin değerlendirilmesi. Gülhane Tip Dergisi 2007;49:25-31. 